\title{
Investigasi Pendugaan Gerakan Tanah Menggunakan Metode Electrical Resistivity Tomography dan Self Potential di Daerah Pasanggrahan Baru, Sumedang Selatan
}

\section{Investigation Estimating of Land Movement Using Methods of Electrical Resistivity Tomography and Self-Potential in Pasanggrahan Baru Area, South Sumedang}

\author{
Budy Santoso $^{1}$, Subagio ${ }^{2}$, Mia Uswatun Hasanah ${ }^{1}$ dan Hilman Suwargana ${ }^{3}$ \\ ${ }^{1}$ Departemen Geofisika FMIPA Unpad, Jalan Raya Bandung Sumedang Km.21, Jatinangor, Sumedang \\ ${ }^{2}$ Pusat Survei Geologi, Jalan Diponegoro No.57 Bandung 40122 \\ ${ }^{3}$ Pusat Pengembangan Sumber Daya Manusia Geologi, Mineral dan Batubara, Jalan Jenderal Sudirman No.623, Bandung 40211 \\ E-mail : budi@geophys.unpad.ac.id \\ Naskah diterima : 24 Februari 2020, Revisi terakhir : 28 Februari 2020 Disetujui : 28 Februari 2020, Online : 28 Februari 2020 \\ DOI: http://dx.doi.org/10.33332/jgsm.geologi.21.33-44p
}

\begin{abstract}
Abstrak- Gerakan tanah terjadi karena adanya pergerakan material pembentuk lereng berupa tanah, batuan atau kombinasi jenis material ke tempat yang lebih rendah karena pengaruh gravitasi. Pergerakan material lereng ini dapat diidentifikasi dengan Metode Electrical Resistivity Tomography (ERT), karena metode ini memiliki resolusi lateral dan vertikal yang baik berdasarkan kerapatan data resistivitas batuan. Faktor pemicu gerakan tanah di Lingkung Anjung, Pasanggrahan Baru, Sumedang Selatan, antara lain adanya peningkatan kadar air di lereng dan bidang gelincir. Peningkatan kadar air dipengaruhi oleh infiltrasi air hujan sebagai salah satu pemicu gerakan tanah dapat dideteksi dengan metode Self Potential (SP), sedangkan bidang gelincir dapat dideteksi dengan metode ERT. Berdasarkan hasil pengukuran ERT dan SP maka diperoleh hasil sebagai berikut: bahan rombakan sebagai bidang longsor (nilai resistivitas: $31-170 \mathrm{Ohm} . \mathrm{m}$ dan nilai SP:5-13 mV), muka air tanah/lapisan jenuh air (nilai resistivitas: 1-13 Ohm.m dan nilai SP:14-34 mV), serta breksi (nilai resistivitas: 400-900 Ohm.m dan nilai SP:1-3 mV). Bidang gelincir diperkirakan batas antara breksi dengan material di atasnya.
\end{abstract}

Katakunci: Gerakan tanah, resistivitas, self potential, Sumedang Selatan

\begin{abstract}
Land movement occur because of the movement of slope-forming material such as of soil, rock or a combination of material types to a place that is lower due to the influence of gravity. The movement of slope material can be identified by the Electrical Resistivity Tomography(ERT) Method, because this method has good lateral and vertical resolution based on rock resistivity data. The trigger factors for land movement in Anjung Village, Pasanggrahan Baru, South Sumedang, among others: an increase in water content on the slopes and the slip plane. Increased water content is influenced by infiltration of rainwater as one of the triggers of land movement, can be detected by the Self Potential method (SP), while the slip plane can be detected by the method of Electrical Resistivity Tomography (ERT). Based on the results of the ERT and SP measurements, the results are: debris flow as a landslide plane (resistivity values: $31-170$ Ohm.m and SP values: $5-13 \mathrm{mV}$ ), water table/water saturated layer (resistivity values: 1 - 13 Ohm.m and SP values: $14-34 \mathrm{mV}$ ), and breccias (resistivity values: 400 - 900 Ohm.m and SP values: 1-3 mV). Slip plane are estimated to be at boundary between the breccia and the material on it.
\end{abstract}

Keywords: Land movement, resistivity, self potential, South Sumedang 


\section{PENDAHULUAN}

Daerah Pasanggrahan Baru, Sumedang Selatan merupakan salah satu lokasi di Sumedang yang rentan gerakan tanah (Gambar 1). Daerah ini berbatasan langsung dengan Jalan Raya Bandung-Cirebon dengan ketinggian antara 560 - $675 \mathrm{~m}$. Gerakan tanah berupa longsoran bahan rombakan di daerah ini terjadi pada bulan September 2016 (Anonim, 2016a), dan sampai saat ini gerakan tanah di lokasi tersebut masih aktif. Gerakan tanah dipicu oleh beberapa faktor, antara lain: infiltrasi air hujan, sudut kemiringan lereng, tutupan lahan, perubahan kelembaban tanah (Varnes, 1978), serta adanya lapisan bidang gelincir yang terdapat pada batuan yang bersifat kedap air (impermeable). Lereng yang mengandung lapisan tanah jenuh air akibat infiltrasi air hujan akan menyebabkan berkurangnya daya ikat tanah dalam tubuh lereng, sehingga lereng menjadi tidak stabil dan akhirnya terjadi longsor (Zakaria dkk., 2015). Longsor adalah fenomena geologi yang terjadi karena pergerakan material pembentuk lereng berupa tanah, batuan, atau kombinasi jenis material tersebut, ke tempat yang lebih rendah karena pengaruh gaya gravitasi (Chowdhury, 2010), serta untuk memperoleh keseimbangan baru akibat pengaruh gangguan dari luar yang menyebabkan terjadinya pengurangan kuat geser dan peningkatan tegangan geser tanah (Sassa dkk., 2009 ; Malamud dkk., 2004).

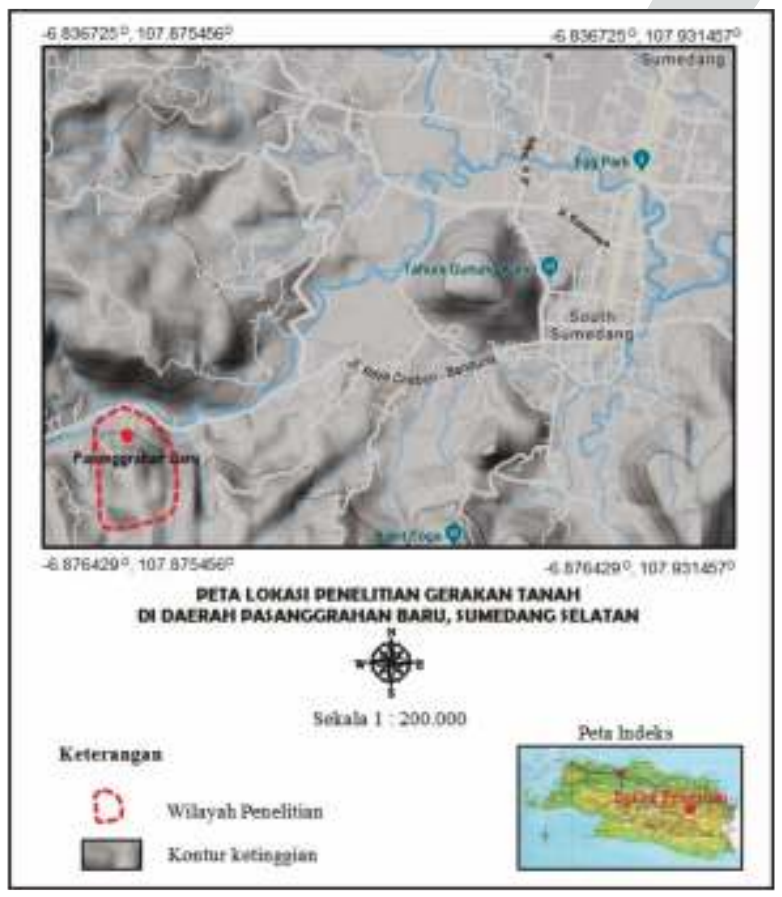

Gambar 1. Peta lokasi penelitian gerakan tanah di daerah Pasanggrahan Baru, Sumedang Selatan (Google Map, 2019).
Beberapa penelitian terdahulu mengenai gerakan tanah telah dilakukan dengan berbagai macam metode kajian, diantaranya: metode Electrical Resistivity Tomography (ERT) untuk mengidentifikasi longsor (Carpentier et al., 2012; Gance et al., 2016; Uhlemann et al., 2015), metode geoteknik untuk memprediksi kestabilan lereng (Tsucida et al., 2014; Yin et al., 2016; Gulla et al., 2018), dan metode Self Potential (SP) untuk mengetahui hidrologi daerah longsor (Colangelo et al., 2006); Bordoni et al., 2015). Kajian gerakan tanah lainnya yang telah dilakukan dengan integrasi data, diantaranya: integrasi data geoteknik dan ERT (Solberg et al., 2016) serta integrasi data SPdan mikrotremor (Wang et al., 2018).

Investigasi gerakan tanah yang dilakukan dalam penelitian ini menggunakan integrasi data geolistrik berupa data ERT dan SP. Teknik integrasi ini untuk investigasi gerakan tanah belum pernah ada yang melakukan. Tujuan penggunaan metode ERT yaitu untuk mendapatkan beberapa indikator yang berkaitan dengan gerakan tanah yang terdapat di bawah permukaan, antara lain: posisi bidang longsor (bidang pergeseran tanah/batuan), posisi dan kedalaman bidang gelincir serta lapisan jenuh air, sedangkan penggunaan metode SP bertujuan untuk mendelineasi sebaran fluida/lapisan jenuh air.

\section{METODE PENELITIAN}

Metode yang digunakan dalam penelitian ini adalah Metode ERT dan SP. Pemilihan Metode ERT dalam penelitian ini didasarkan pertimbangan bahwa metode tersebut memiliki resolusi lateral dan vertikal yang sangat baik, sehingga dapat mendeteksi pergeseran yang terjadi pada lapisan batuan berdasarkan kontras resistivitas batuan. Metode Self Potential digunakan untuk mendelineasi sebaran air tanah (muka air tanah) yang berkaitan secara tidak langsung dengan keberadaan bidang gelincir selain itu kelebihan lainnya adalah efesiensi dalam pengukuran di lapangan.

\section{Metode Electrical Resistivity Tomography (ERT)}

Metode ERT adalah metode pengukuran resistivitas di permukaan tanah dengan menggunakan banyak elektroda, agar diperoleh variasi distribusi resistivitas bawah permukaan (Daily et al., 2004).

Dalam pengukuran ERT, panjang lintasan yang diukur adalah $240 \mathrm{~m}$ dengan jarak antar elektroda $6 \mathrm{~m}$ dan jumlah elektroda 41 buah. Skema pengukuran Electrical Resistivity Tomography (ERT) ditunjukkan pada Gambar 2. 


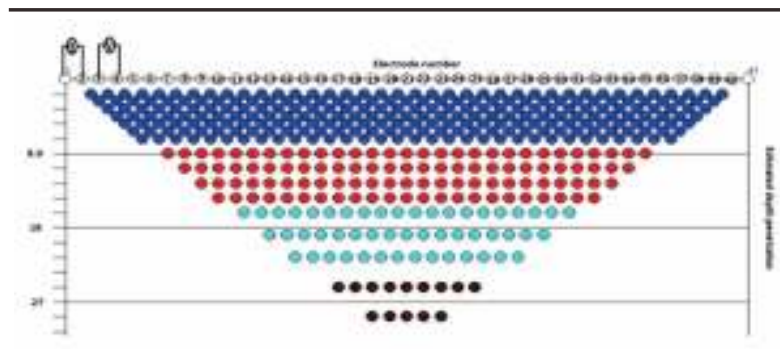

Gambar 2. Skema pengukuran Electrical Resistivity Tomography (ERT) menggunakan Konfigurasi Dipole-Dipole dengan 41 elektroda (I: elektroda arus, V: elektroda potensial).

Persamaan yang digunakan untuk menghitung resistivitas semu dengan Konfigurasi Dipole-Dipole (Telford et al., 2004) sebagai berikut:

$$
\rho_{s}=n(n+1)(n+2) \pi a \frac{\Delta V}{T}
$$

dengan, ps: resistivitas semu (Ohm.m), DV: beda potensial (V), I: arus yang diinjeksikan (A), dan a : jarak antara pasangan elektroda arus dan elektroda potensial $(\mathrm{m})$.

Peralatan yang digunakan dalam pengukuran ERT, yaitu satu unit Resistivity Meter Naniura Multielectrodes NRD $300 \mathrm{Hf}$ dengan 41 elektroda. Data mentah (resistivitas semu) yang diperoleh dalam pengukuran ERT disimpan dalam format *.dat, untuk memperoleh nilai resistivitas sebenarnya maka dilakukan pemodelan resistivitas dengan Metode Inversi Least-Square (Loke, 2004).

\section{Metode Self Potential}

Metode Self Potential (SP) adalah salah satu metode geolistrik yang merupakan metode pasif karena pengukurannya dilakukan tanpa menginjeksikan arus listrik ke permukaan tanah, perbedaan potensial alami tanah diukur melalui dua titik dipermukaan tanah. Potensial yang dapat diukur berkisar antara beberapa millivolt $(\mathrm{mV})$ sampai dengan 1 volt. Self potential dipicu oleh aliran air dalam medium berpori yang dinamakan potensial elektrokinetik.

Anomali SP jika dihubungkan dengan Hukum Darcy (Kodoatie, 1996), akan diperoleh persamaan sebagai berikut:

$$
\mathrm{v}=\mathrm{KVH}=\frac{\mathrm{K}}{\mathrm{c}} \mathrm{\nabla V}
$$

dengan $\mathrm{v}$ adalah kecepatan aliran fluida air $\left(\mathrm{LT}^{-1}\right), \mathrm{K}$ : permeabilitas intrinsik $\left(\mathrm{L}^{2}\right), \mathrm{K}$ : konduktivitas hidrolik (cm/det) $\eta$ : viskositas dari fluida $\left(\mathrm{ML}^{-1} \mathrm{~T}^{-1}\right) \mathrm{C}$ : koefisien potensial elektro hidrolik $(\mathrm{mV} / \mathrm{cm})$

$$
\text { vv : gradien potensial elektrokinetik }\left(\mathrm{MLI}^{-1} \mathrm{~T}^{-3}\right) \text {. }
$$

Persamaan (2) menjelaskan hubungan kecepatan aliran fluida dengan anomali potensial elektrokinetik atau SP dalam medium. Berdasarkan hubungan tersebut, maka kecepatan aliran berbanding lurus dengan besarnya SP. Jika kecepatan perembesan air dalam tanah semakin tinggi maka respon potensial dipermukaan akan semakin tinggi pula.

Metode akuisisi data yang digunakan dalam pengukuran self potential yaitu metode leap frog dan fixed base. Dalam Metode Leap-Frog (Gambar 3.a), kedua porous pot bergerak (berpindah-pindah)untuk setiap pengukuran dengan jarak antar porous pot yang sama, sedangkan dalam Metode fixed base (Gambar 3.b) salah satu porous pot berada pada satu titik tetap (titik referensi) dan porous pot lainnya bergerak/berpindahpindah menjauhi titik referensi untuk setiap pengukuran. Panjang lintasan pengukuran SP adalah $234 \mathrm{~m}$, sedangkan jarak antar porous pot adalah $6 \mathrm{~m}$. Peralatan yang digunakan dalam pengukuran self potential terdiri dari: satu unit Multimeter Digital Fluxegate dengan porous pot.

Diagram alir penelitian mulai dari akuisisi data, pengolahan data dan interpretasi ditunjukkan pada Gambar 4.

\section{GEOLOGI DAERAH PENELITIAN}

Menurut Van Bemmelen (1949) daerah Sumedang terletak pada zona Bogor sebelah timur, membentang dari Barat ke Timur mulai dari Rangkasbitung, Bogor, Subang, Sumedang, dan berakhir di Bumiayu dengan panjang $\pm 40 \mathrm{~km}$. Daerah ini merupakan perbukitan lipatan yang terbentuk dari batuan sedimen tersier laut dalam membentuk suatu antiklonirarium, di beberapa tempat mengalami patahan yang diperkirakan pada Kala Pliosen-Plistosen bersamaan dengan terbentuknya patahan Lembang dan pengangkatan Pegunungan Selatan.

Secara umum geomorfologi daerah penelitian Lingkung Anjung, Pasanggrahan Baru, Sumedang Selatan , merupakan perbukitan berundulasi, dengan kemiringan lereng: $25-70^{\circ}$ dan elevasi $560-675 \mathrm{~m}$ di atas permukaan laut (Gambar 5). Perbukitan merupakan daerah yang rentan terjadinya gerakan tanah (Bell, dkk., 2012), sehingga apabila mengalami gerakan tanah akan menyebabkan perubahan bentuk geomorfologi yang dapat merusak perumahan penduduk dan infrastruktur (Crozier, 2010; Korup, dkk., 2010). 


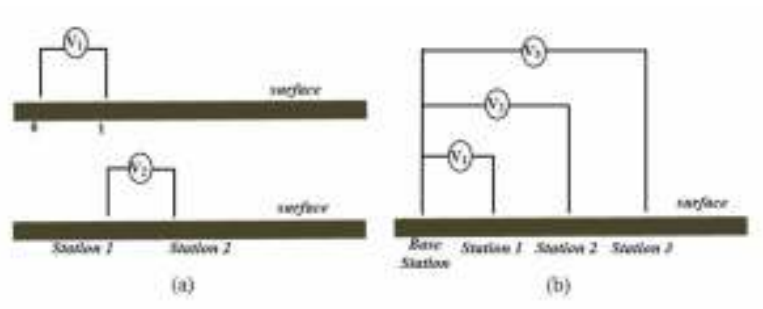

Gambar 3. Konfigurasi SP, a. Leap-Frog Method, b. FixedBase Method.

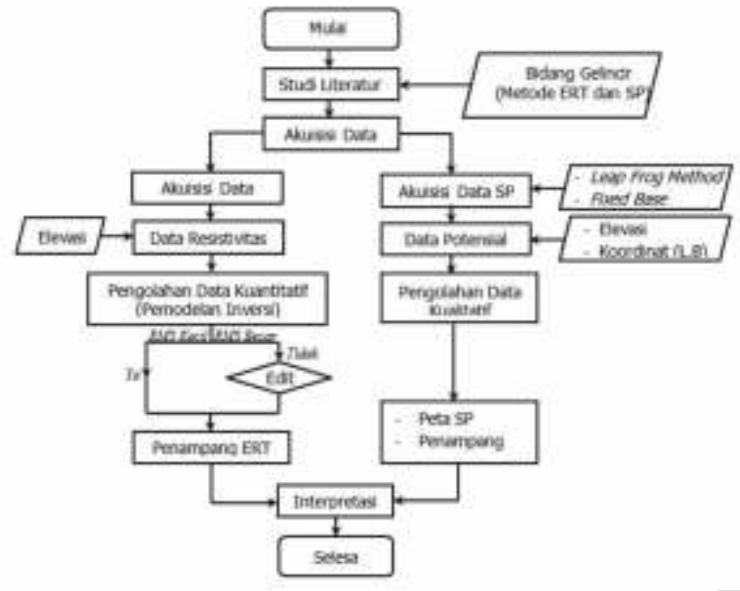

Gambar 4. Diagram alir penelitian.

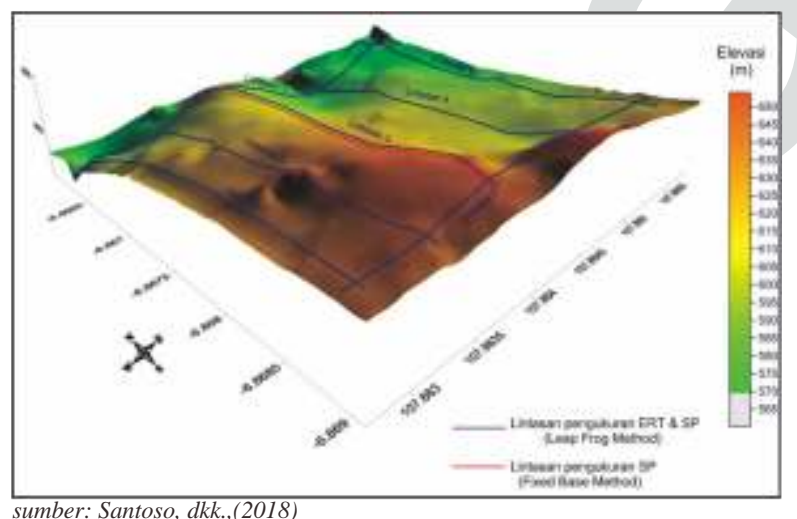

Gambar 5. Geomorfologi Lingkung Anjung, Pasanggrahan Baru, Sumedang Selatan.

Menurut Silitonga (1973) dalam Peta Geologi Regional Lembar Bandung, skala 1:100.000, geologi daerah penelitian terdiri atas: breksi gunungapi dan aliran lahar bersusunan andesit - basal (hasil gunungapi tua breksi, Qvb), lava gunungapi yang menunjukkan kekar lempeng dan kekar tiang hasil dari gunungapi tua $(\mathrm{Qvl})$, pasir tufan, lapili, breksi, lava dan aglomerat yang sebagian berasal dari G. Tangkubanparahu dan G. Tampomas (Qyu).

Tanah pelapukan di daerah pemukiman berupa tuf yang teralterasi menjadi lempung pasiran berwarna coklat kekuningan sampai coklat kemerahan.

\section{HASIL PENELITIAN}

\section{Indikasi Gerakan Tanah Aktif}

Berdasarkan Peta Zona Kerentanan Gerakan Tanah (Anonim, 2008), tingkat kerentanan gerakan tanah di daerah penelitian termasuk ke dalam zona kerentanan gerakan tanah menengah-tinggi (Gambar 6), artinya daerah ini dapat terjadi gerakan tanah jika curah hujan di atas normal. Potensi Gerakan tanah terdapat pada lokasi yang berbatasan dengan jalan, gawir dan pada lereng yang mengalami gangguan.

Beberapa indikasi bahwa di lokasi penelitian gerakan tanahnya masih aktif (Gambar 7), antara lain: erosi tanah aktif, hal ini bisa dilihat pada jalan setapak (anak tangga) yang mengalami pengikisan/erosi tanah; dinding rumah dengan posisi miring; dan adanya retakan pada lantai, dinding rumah dan tembok pagar rumah warga serta retakan pada jalan setapak.

Apabila hal tersebut terus dibiarkan, maka akan mengancam rumah warga dan terputusnya jalan raya Bandung - Sumedang - Cirebon.

\section{HAsil Analisis Electrical ResistivitY Tomography (ERT)}

\section{a. Penampang ERT Lintasan 1}

Pada Gambar 8 ditunjukkan penampang ERT lintasan 1. Pada jarak 48 m, 112 m, 138 m, 156 m, 190 m, dan 208 m, terdapat pola melensa dengan nilai $72-170 \mathrm{Ohm}$.m yang diduga sebagai aliran bahan rombakan yang merupakan bidang longsor/bidang pergeseran tanah. Bahan rombakan di daerah penelitian terdiri dari: tanah lapukan, pasir tufan, kerakal, dan fragmen batuan lainnya yang bercampur dengan air.

Pada lapisan di bawahnya terdapat resistivitas rendah dengan nilai 1 - 13 Ohm.m yang diduga sebagai pasir tufan dan ditafsirkan merupakan muka air tanah (water table). Lapisan di bawahnya terdapat resistivitas dengan nilai $171-400 \mathrm{Ohm}$.m yang diduga sebagai breksi tufan, sedangkan lapisan paling bawah terdapat nilai resistivitas tinggi $>400 \mathrm{Ohm}$.m yang diduga sebagai breksi. Permukaan Breksi dapat berfungsi sebagai bidang gelincir, karena diperkirakan memiliki sifat kedap air (impermeable), artinya air yang terdapat pada batuan tersebut tidak dapat dialirkan ke lapisan di bawahnya, tetapi akan dialirkan ke bawah searah kemiringan lereng.

Pada lapisan dekat permukaan terdapat indikasi struktur berupa rekahan terdapat pada jarak $90 \mathrm{~m}, 114 \mathrm{~m}$, dan 144 m. Struktur rekahan ini merupakan zona lemah yang memudahkan air hujan meresap ke dalam tanah. 


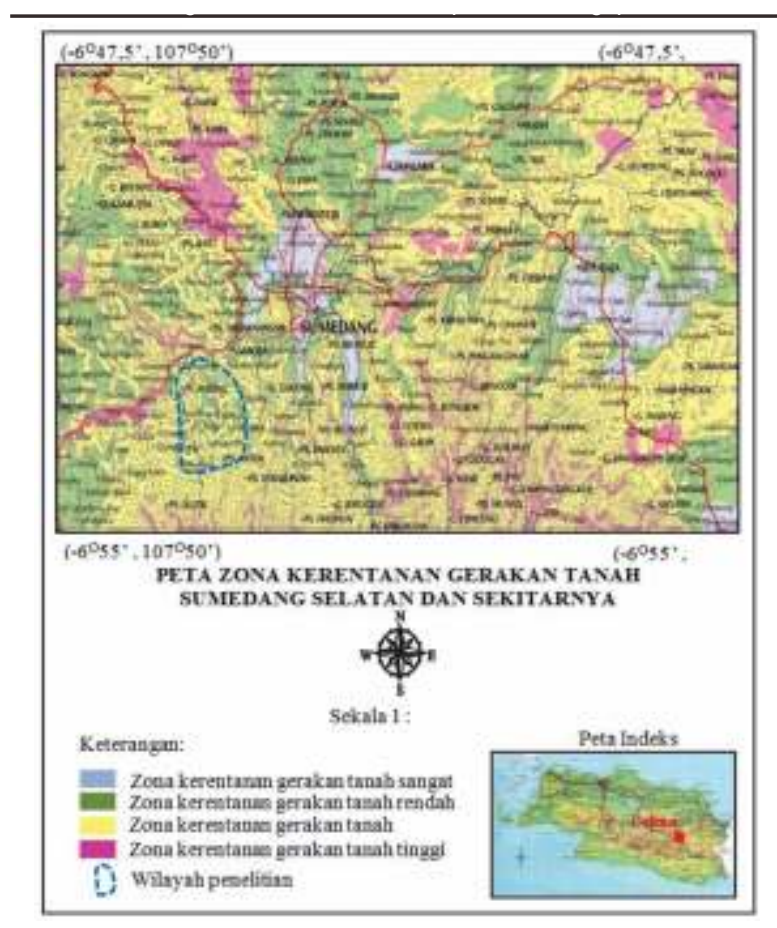

sumber:modifikasi Peta Zona Kerentanan Gerakan Tanah Kabupaten Sumedang, PVMBG (2008)

Gambar 6. Peta zona kerentanan gerakan tanah Sumedang Selatan dan sekitarnya.

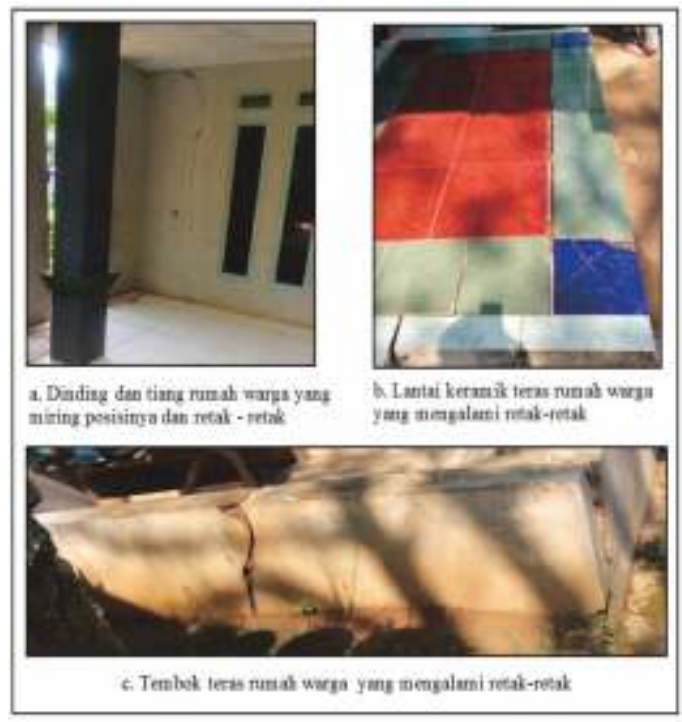

Gambar 7. Kondisi rumah warga yang mengalami retak-retak akibat adanya gerakan tanah yang masih aktif di lokasi penelitian.

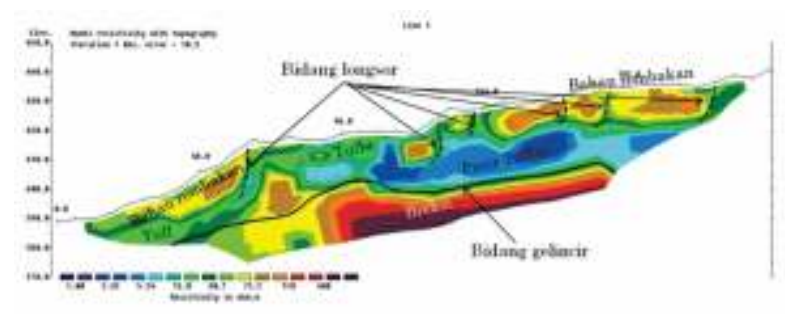

Gambar 8. Penampang ERT Lintasan 1.
Terjadinya gerakan tanah pada lintasan 1 diduga karena adanya peningkatan infiltrasi air hujan, kemudian air hujan tersebut meresap ke lapisan batuan dibawahnya sampai ke lapisan yang kedap air (impermeable) yang diduga breksi (resistivitas > 400 Ohm.m). Jika hujan berlangsung terus menerus maka air yang terkandung dalam tanah akan terus bertambah dan suatu saat menjadi jenuh air, sehingga daya ikat tanah berkurang, akibatnya tanah tersebut mengalami pergeseran dan bergerak searah kemiringan lereng.

\section{b. Penampang ERT Lintasan 2}

Pada Gambar 9 ditunjukkan penampang ERT lintasan 2. Pada lapisan dekat permukaan terdapat indikasi struktur berupa rekahan pada jarak $60 \mathrm{~m}, 102 \mathrm{~m}$, dan $144 \mathrm{~m}$. Struktur rekahan ini merupakan zona lemah yang membantu proses infiltrasi air hujan ke dalam tanah sehingga dapat mempercepat terjadinya proses pelapukan.

Pada jarak 18 m, 48 m, 72 m, 118 m, 156 m, dan 192 m, terdapat pola melensa dengan nilai resistivitas $31-170$ Ohm.m yang diduga sebagai bahan rombakan yang mengalami pergeseran karena materialnya bersifat lepas. Aliran bahan rombakan terjadi karena lapisan tersebut jenuh air sehingga daya ikat tanah berkurang, akibatnya terjadinya pergeseran batuan yang bergerak searah kemiringan lereng.

Pergeseran bahan rombakan tersebut selain disebabkan oleh lapisan batuan yang jenuh air, disebabkan juga oleh adanya lapisan bidang gelincir. Indikasi bidang gelincir pada penampang ERT lintasan 2 terdapat pada permukaan yang diduga breksi dengan nilai resistivitas 400 - 900 Ohm.m. Breksi bersifat kedap air sehingga permukaannya dapat berfungsi sebagai sebagai bidang gelincir.

\section{c. Penampang ERT Lintasan 3}

Pada Gambar 10 ditunjukkan penampang ERT lintasan 3. Indikasi pergeseran tanah/batuan berupa bahan rombakan (tanah lapukan, pasir tufan, kerakal, dan fragmen batuan lainnya yang bercampur dengan air) dengan nilai resistivitas $31-170 \mathrm{Ohm} . \mathrm{m}$, terdapat pada jarak 6 - $48 \mathrm{~m}, 96 \mathrm{~m}$, dan $168 \mathrm{~m}$. Pada lapisan di bawahnya terdapat resistivitas rendah dengan nilai $1-13$ Ohm.m yang diduga sebagai pasir tufan, lapisan ini memiliki porositas tinggi sehingga mengandung air (muka air tanah /water table). Pada lapisan di bawahnya terdapat lapisan kedap air yang diduga breksi dengan nilai resistivitas 400 - 900 Ohm.m, batas antara dua lapisan ini berfungsi sebagai bidang gelincir.

Indikasi diduga struktur berupa rekahan terdapat pada 
lapisan dekat permukaan dengan jarak $66 \mathrm{~m}$ dan 204 $\mathrm{m}$, sedangkan diduga struktur patahan terdapat pada lapisan dengan kedalaman 20 - $30 \mathrm{~m}$ pada jarak 126 m. Struktur rekahan dan patahan ini merupakan bidang lemah yang memudahkan air hujan meresap ke dalam tanah, sehingga mempercepat terjadinya pelapukan batuan. Pelapukan pada batuan menghasilkan batuan lapuk dan tanah residual penyusun lereng.

\section{d. Penampang ERT Lintasan 4}

Pada Gambar 11 ditunjukkan penampang ERT lintasan 4. Indikasi aliran bahan rombakan dengan nilai resistivitas $31-170 \mathrm{Ohm} . \mathrm{m}$ terdapat pada jarak $156-240 \mathrm{~m}$, lapisan ini sebelumnya tidak mengalami pergeseran tetapi karena adanya longsoran $42-204$ $\mathrm{m}$ dan kedalaman $7-20 \mathrm{~m}$, mengakibatkan lapisan batuan tersebut bergeser dari posisi semula.

Indikasi bidang gelincir yang merupakan salah satu faktor pemicu terjadinya gerakan tanah pada breksi dengan nilai resistivitas $>400 \mathrm{Ohm} . \mathrm{m}$ terdapat pada lapisan paling bawah dengan kedalaman $10-21 \mathrm{~m}$. Pada lapisan dekat permukaan terdapat indikasi struktur berupa rekahan pada jarak $120 \mathrm{~m}$ dan $186 \mathrm{~m}$. Struktur rekahan ini akan mempercepat infiltrasi air hujan ke dalam tanah sehingga dapat mempercepat terjadinya proses pelapukan pada batuan.

\section{e. Penampang ERT Lintasan 5}

Pada Gambar 12 ditunjukkan penampang ERT lintasan 5. Indikasi struktur rekahan terdapat pada lapisan dekat permukaan pada jarak $72 \mathrm{~m}, 120 \mathrm{~m}, 138$ $\mathrm{m}, 186 \mathrm{~m}$, dan $228 \mathrm{~m}$, sedangkan pada lapisan batuan dengan kedalaman $+25 \mathrm{~m}$ pada jarak $96 \mathrm{~m}$, terdapat indikasi struktur patahan. Struktur rekahan dan patahan merupakan bidang lemah kaRena air akan mudah masuk ke dalam tanah, sehingga mempercepat terjadinya proses pelapukan dan pergeseran batuan.

Pada lapisan dekat permukaan dengan jarak 30 - 60 m, $144 \mathrm{~m}$, dan $204-210 \mathrm{~m}$, terdapat pola melensa dengan nilai resisitivitas $72-170$ Ohm.m yang diduga sebagai bahan rombakan. Pergerakan tanah pada bahan rombakan (tanah lapukan, pasir tufan, kerakal, dan fragmen batuan lainnya yang bercampur dengan air) terjadi karena dipicu oleh peningkatan air hujan yang masuk melalui struktur rekahan, kemudian air hujan tersebut masuk ke lapisan di bawahnya sampai ke lapisan yang kedap air yang diduga sebagai breksi (nilai resistivitas: 400 - 900 Ohm.m). Apabila infiltrasi air hujan sampai pada lapisan bidang gelincir, maka air tersebut sudah tidak bisa meresap ke lapisan di bawahnya. Apabila infiltrasi air hujan terus berlangsung akan mengakibatkan lapisan tersebut jenuh air. Akibatnya massa tanah/batuan akan bertambah dan daya ikat tanahnya menjadi berkurang, sehingga batuan yang telah bercampur dengan tanah lapuk dan air akan bergerak searah kemiringan lereng.

\section{f. Penampang ERT Lintasan 6}

Pada Gambar 13 ditunjukkan Penampang ERT lintasan 6. Lintasan 6 ini berarah Barat-Timur/tegak lurus

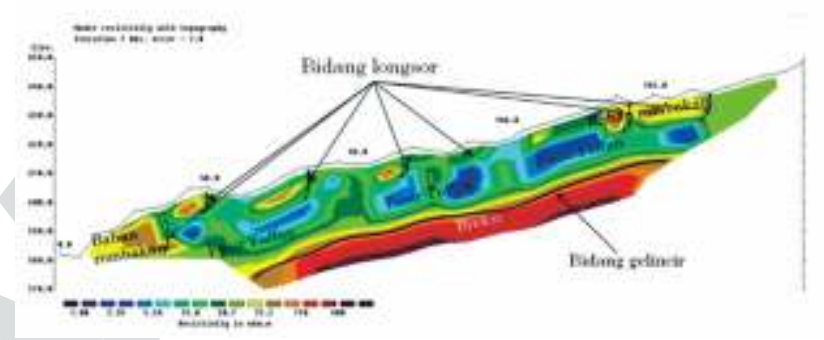

Gambar 9. Penampang ERT Lintasan 2.

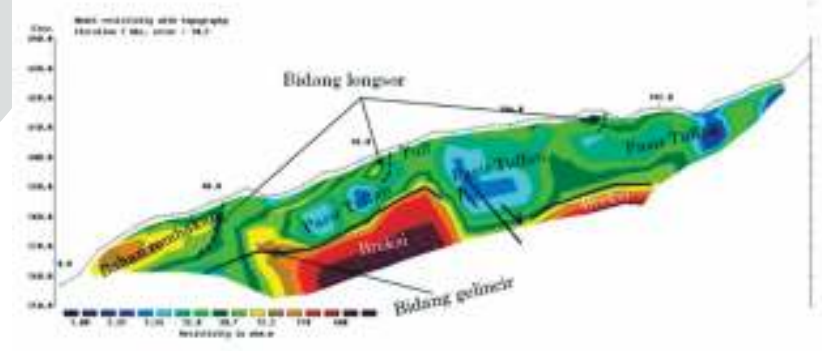

Gambar 10. Penampang ERT Lintasan 3.

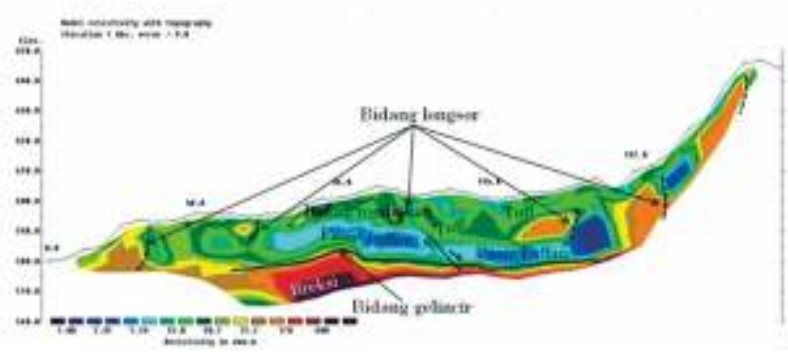

Gambar 11. Penampang ERT Lintasan 4.

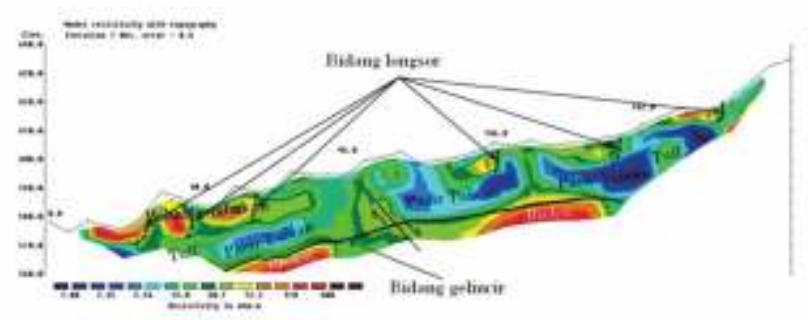

Gambar 12. Penampang ERT Lintasan 5. 
lintasan 1, 2, 3, 4, 5 (sejajar lereng). Pada lapisan paling atas terdapat resistivitas dengan nilai $31-170$ Ohm.m yang diduga sebagai bahan rombakan (tanah lapukan, pasir tufan, kerakal, dan fragmen batuan lainnya yang bercampur dengan air).

Pada lapisan di bawahnya terdapat resistivitas rendah dengan nilai 1 - 13 Ohm.m, yang diduga sebagai pasir tufan dengan porositas tinggi, sehingga lapisan ini mengandung air. Pada lapisan di bawahnya terdapat nilai resistivitas $14-30 \mathrm{Ohm} . \mathrm{m}$ yang diduga sebagai tuf. Pada lapisan paling bawah terdapat resistivitas tinggi dengan nilai $>400 \mathrm{Ohm} . \mathrm{m}$ yang diduga sebagai breksi tufan yang bersifat kedap air.

\section{g. Penampang ERT Lintasan 7}

Pada Gambar 14 ditunjukkan penampang ERT lintasan 7. Penampang ini berarah barat-timur atau tegak lurus lintasan 1, 2, 3, 4, dan lintasan 5. Pada lapisan paling atas terdapat resistivitas dengan nilai 72 - 400 Ohm.m yang diduga sebagai bahan rombakan dan terdapat pada jarak 0 - 96 m, $192-196$ $\mathrm{m}$, dan $240 \mathrm{~m}$. Pada lapisan di bawahnya terdapat resistivitas tinggi : (400 - $900 \mathrm{Ohm} . \mathrm{m})$ bersifat masif dan diduga sebagai breksi, terdapat di sepanjang penampang dengan kedalaman $2-20 \mathrm{~m}$. Breksi bersifat kedap air (impermeable) sehingga batas permukaan breksi dengan material lainnya yang lolos air bisa berfungsi sebagai bidang gelincir.

\section{Hasil Analisis Metode Self Potential}

Pada Gambar 15 menampilkan Peta Self Potential Lingkung Anjung, Pasanggrahan Baru, Sumedang

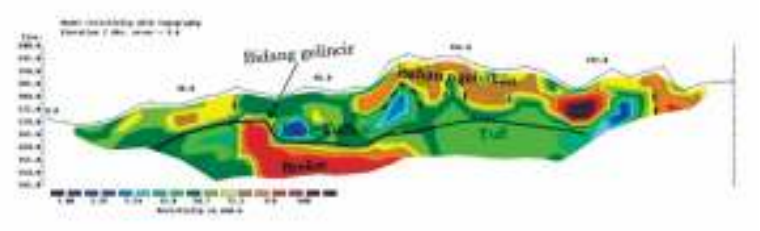

Gambar 13. Penampang ERT Lintasan 6.

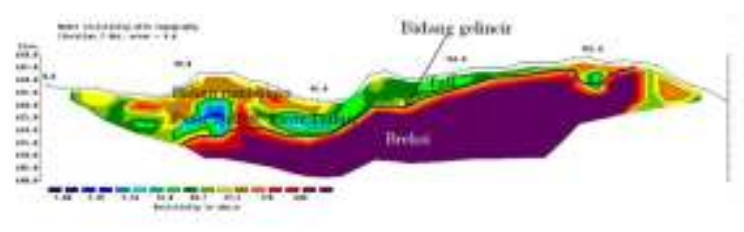

Gambar 14. Penampang ERT Lintasan 7.
Selatan dengan beberapa variasi interval porous pot. Semakin lebar interval porous pot maka anomali yang diperoleh akan semakin dalam. Untuk menentukan kedalaman anomali SP dapat diperoleh dengan pemodelan inversi SP. Dalam penelitian ini pemodelan SP tidak dilakukan karena tujuannya hanya untuk keperluan interpretasi secara kualitatif, sedangkan untuk menentukan kedalaman anomali secara kuantitatif menggunakan pemodelan inversi dari data ERT karena lebih akurat dibandingkan dengan pemodelan inversi SP.

Secara umum pola anomali SP dengan interval porous pot $0-6 \mathrm{~m}$ (Gambar 15a) dan interval porous pot $0-12 \mathrm{~m}$ (Gambar 15b), mempunyai pola yang sama yaitu berarah Utara-Selatan. Anomali SP bernilai tinggi: $(14-34 \mathrm{mV})$ diduga merupakan zona muka air tanah (lapisan jenuh air) yang terletak di sebelah barat, dan merupakan zona lemah (memiliki resiko longsor tinggi) karena lapisan jenuh air ini kontak langsung dengan batuan sebagai bidang gelincir (breksi). Luas sebaran muka air tanah/lapisan jenuh air di sebelah barat terjadi karena beberapa faktor, antara lain: adanya struktur rekahan dan patahan yang dapat mempercepat proses infiltrasi air hujan, pelapukan batuan dan adanya lapisan kedap air (permukaan breksi) yang berfungsi sebagai bidang gelincir, sehingga ketika lapisan tersebut jenuh air maka air tersebut akan menyebar secara lateral dan bergerak searah kemiringan lereng.

Nilai SP rendah $(<14 \mathrm{mV})$ yang terdapat di sebagian besar daerah Timur mengindikasikan bahwa lapisan tersebut lebih padat dibandingkan di sebelah Barat pada kedalaman yang sama. Rendahnya nilai SP $(<14 \mathrm{mV})$ di sebelah Timur dapat diakibatkan oleh beberapa faktor, diantaranya: sedikitnya struktur rekahan/ patahan sehingga proses infiltrasi berlangsung lambat, selain itu diduga pula adanya batuan dengan porositas tinggi yang dapat menyimpan air tanah sebarannya sedikit.

Pada Gambar 15c menampilkan Peta Self Potential (interval porous pot: $0-18 \mathrm{~m}$ ) dan Gambar $15 \mathrm{~d}$ menampilkan Peta Self Potential (interval porous pot: 0 $24 \mathrm{~m}$ ). Anomali SP tinggi pada peta SP memiliki pola yang berarah utara-selatan dan utara-barat, sedangkan pola anomali SP tinggi pada peta SP berarah utaraselatan dengan sebaran anomali yang lebih luas ke arah barat dan timur dibandingkan dengan Peta Anomali SP (interval porous pot: $0-6 \mathrm{~m}, 0-12 \mathrm{~m}$, dan $0-18 \mathrm{~m}$ ).

Sebaran anomali SP tinggi $>14 \mathrm{mV}$ pada peta anomali SP (interval porous pot : $0-18 \mathrm{~m}$ dan $0-24 \mathrm{~m}$ ) berkaitan dengan sebaran lapisan pasir tufan yang memiliki porositas tinggi, sehingga dapat menyimpan air tanah, selain itu dipengaruhi pula oleh struktur bawah permukaan (patahan/rekahan). Anomali SP rendah (5 $13 \mathrm{mV}$ ) diduga merupakan aliran bahan rombakan 
(debris flow), sedangkan nilai SP $1-5 \mathrm{mV}$ diduga merupakan lapisan padat yaitu breksi. Breksi tersebut terdapat pada lapisan dangkal (dekat permukaan) sampai lapisan dalam.

\section{DISKUSI}

\section{Penentuan Nilai Self Potential (SP) dan Resistivitas Batuan}

Nilai SP dan resistivitas batuan daerah penelitian ditentukan berdasarkan korelasi data SP, resistivitas dan geologi. Berdasarkan geologi regional (Gambar 16), daerah penelitian tersusun oleh breksi gunungapi dan aliran lahar dalam Satuan Hasil Gunungapi Tua Breksi (Qvb) serta pasir tufan, lapili, breksi, lava dan aglomerat dari Satuan Hasil Gunungapi Muda Tak Teruraikan (Qyu; Silitonga, 1973). Gerakan tanah yang terjadi berupa longsoran bahan rombakan pada tebing di atas badan jalan dengan kemiringan sangat terjal. Tanah pelapukan di daerah pemukiman (penelitian) berupa tuf yang teralterasi menjadi lempung pasiran berwarna coklat kekuningan sampai coklat kemerahan, dengan ketebalan antara 3-6 meter, yang kontak langsung dengan batuan breksi sebagai bidang gelincir (Anonim, 2016b).

Batuan kompak/padat (porositas kecil/tidak memiliki porositas) memiliki resistivitas lebih besar dan SP lebih kecil dibandingkan batuan lunak/tidak padat atau batuan yang dapat menyimpan air (porositas tinggi dan SP tinggi; Telford et al., 2004). Di daerah penelitian batuan yang bersifat keras/padat dan porositas kecil adalah breksi. Batuan tersebut memiliki nilai resistivitas besar dan SP kecil. Resistivitas paling kecil yaitu pasir tufan karena dapat menyimpan air akan memiliki resistivitas paling kecil dan SP paling besar.

Pada Gambar 17a menampilkan Penampang SP dengan Metode Fixed Base, pada jarak: 15 m, 70 m, $100 \mathrm{~m}, 165 \mathrm{~m}, 190 \mathrm{~m}, 210 \mathrm{~m}$, dan $230 \mathrm{~m}$ terdapat pola melensa di dekat permukaan dengan nilai $6-15 \mathrm{mV}$ yang diduga sebagai bahan rombakan yang telah mengalami pergeseran. Pergeseran batuan ini kemungkinan terjadi karena daya ikat tanah/batuan berkurang karena pengaruh lapisan tanah yang jenuh air. Nilai Self Potential tinggi $(16-44 \mathrm{mV})$ diduga sebagai lapisan jenuh air/muka air tanah, diperkirakan sumber airnya berasal dari infiltrasi air hujan yang merembes ke dalam tanah melalui struktur rekahan batuan yang terdapat dipermukaan, dan mengalir dari bagian atas tebing menuju lereng.

Pada Gambar 17b menampilkan Penampang ERT (kedalaman: $+25 \mathrm{~m}$ ) dengan posisi lintasan pengukuran yang sama dengan lintasan pengukuran SP. Pada jarak $18 \mathrm{~m}, 48 \mathrm{~m}, 72 \mathrm{~m}, 118 \mathrm{~m}, 156 \mathrm{~m}, 162 \mathrm{~m}$, dan $192 \mathrm{~m}$, terdapat pola melensa dengan nilai $31-170 \mathrm{Ohm} . \mathrm{m}$ yang diduga sebagai bahan rombakan. Pada lapisan paling bawah terdapat nilai resistivitas rendah $(1-13$ Ohm.m) yang diduga sebagai pasir tufan yang mengandung air (muka air tanah/water table).

Secara umum setelah dikorelasikan, anomali SP dan anomali ERT memiliki pola yang hampir sama, yaitu pola melensa untuk indikasi bahan rombakan (SP $<14$ mV dan ERT: 31 - 170 Ohm.m) yang menunjukkan material bersifat lepas (indikasi gerakan tanah) dan pola

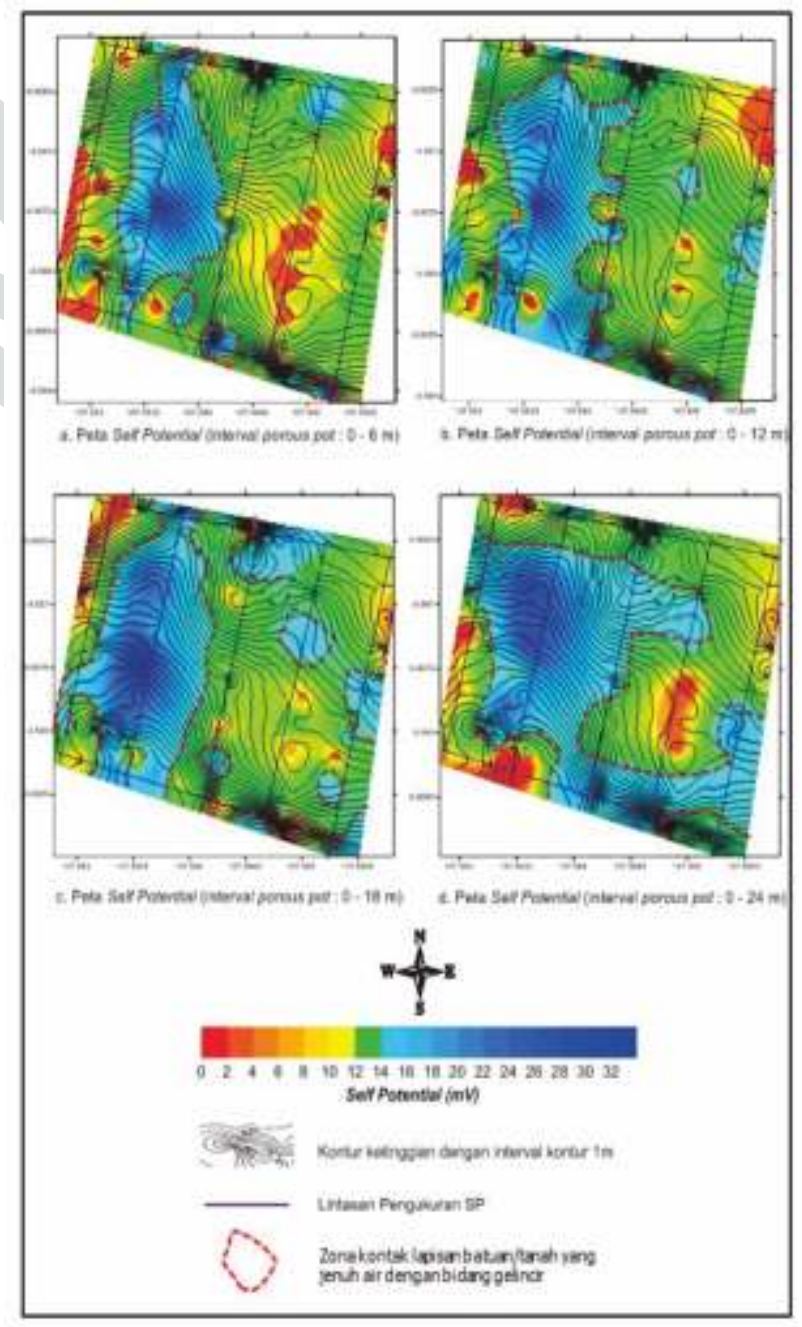

Gambar 15. Peta Self Potential (SP) daerah Pasanggrahan Baru, Sumedang Selatan. 


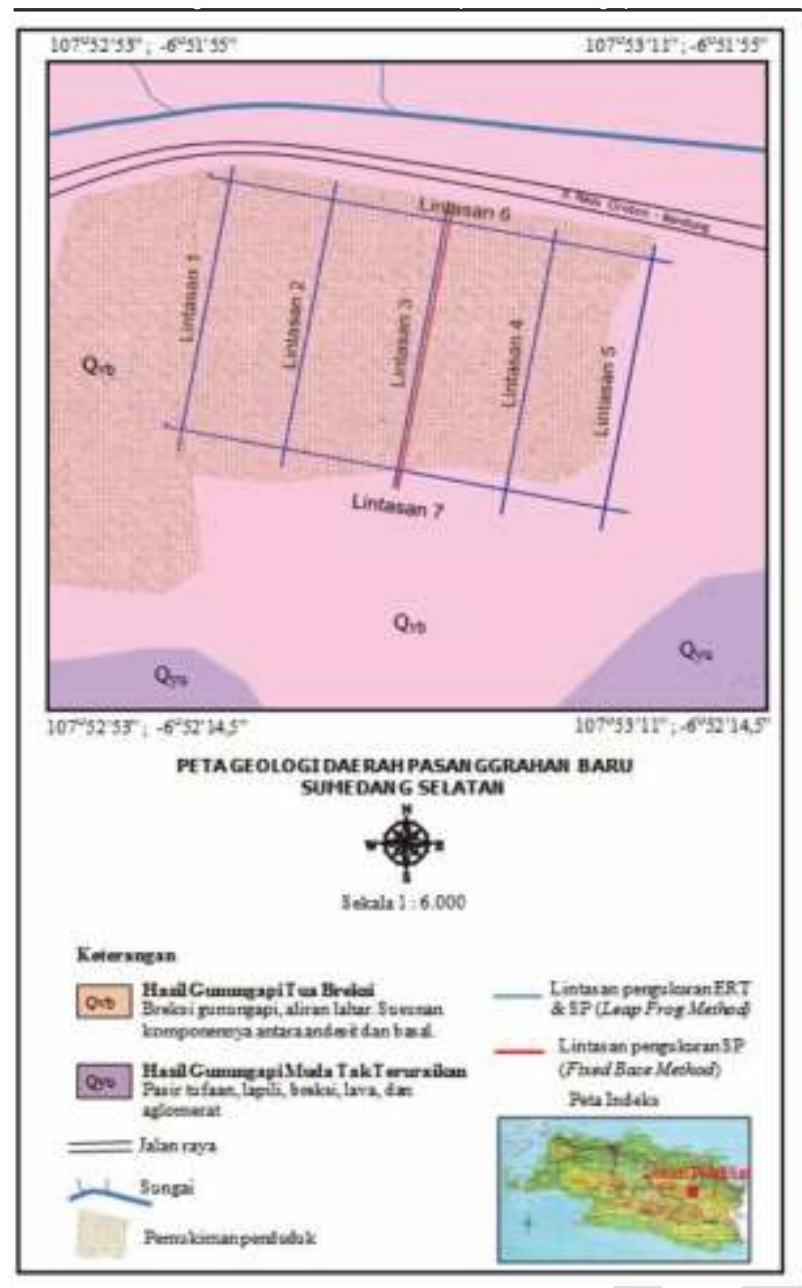

Gambar 16. Peta geologi daerah Pasanggrahan Baru, Sumedang Selatan (modifikasi dari Peta Geologi Lembar Bandung; Silitonga, 1973).

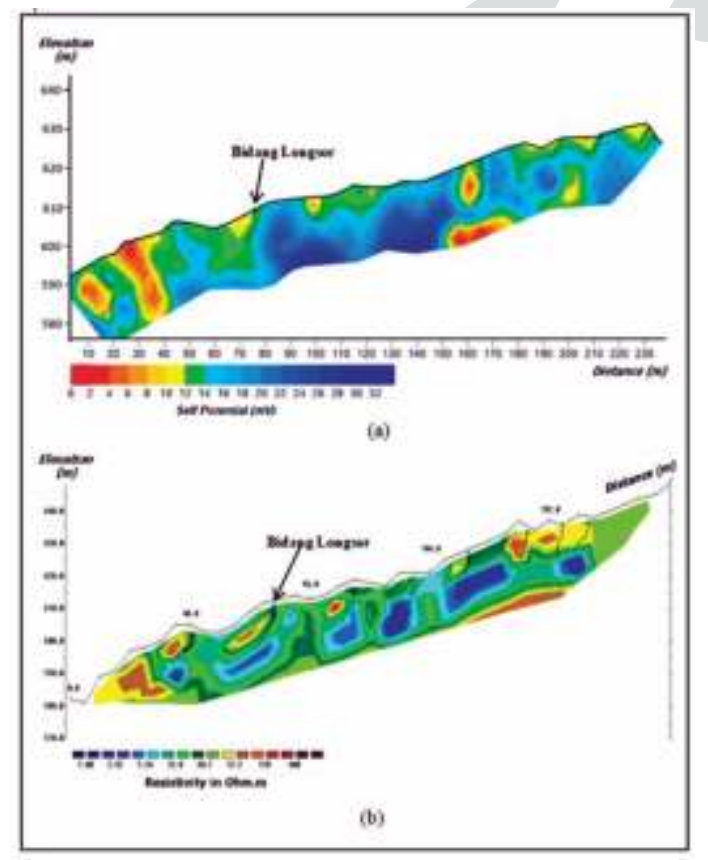

Gambar 17 a. Penampang Self Potensial (Fixed Base Method) Lintasan 2 dan b. Penampang ERT lintasan 2 (depth : 25m) dengan resolusi data mendekati data SP dengan tujuan agar Penampang ERT dapat dikorelasi dengan Penampang SP. membaji yang mengindikasikan muka air tanah/lapisan jenuh air (SP >14 mV dan ERT: 1 - 13 Ohm.m). Berdasarkan hasil korelasi nilai ERT dan nilai SP di lokasi penelitian yang telah dikorelasi geologi setempat ditunjukkan pada Tabel 1.

Resistivitas batuan daerah lain dengan kondisi geologi yang hampir mirip yang telah dikelompokkan nilai resistivitasnya oleh peneliti terdahulu ditunjukkan pada Tabel 2 (Mohammad dkk.,2016).

\section{Indikasi Gerakan Tanah Berdasarkan Korelasi Data ERT dan SP}

Indikasi gerakan tanah yang terdapat di bawah permukaan secara lateral dan vertikal dapat di identifikasi dari data ERT dan SP. Data ERT digunakan untuk menentukan bidang pergeseran batuan atau bidang longsor yang terdapat di bawah permukaan secara lateral-vertikal, menentukan bidang gelincir, serta menentukan lapisan jenuh air. Posisi bidang pergeseran batuan dan bidang gelincir dari penampang ERT diperlukan untuk desain penguatan lereng, yaitu dalam menentukan posisi pondasi tiang pancang (bor pile). Data SP digunakan untuk menzonasi atau mendelineasi area sebaran lapisan jenuh air secara lateral (Gambar 15).

Berdasarkan hasil korelasi SP dan ERT didapatkan beberapa anomali yang berkaitan dengan gerakan tanah, sebagai berikut:

Tabel 1. Nilai resistivitas dan self potential daerah penelitian

\begin{tabular}{lcc}
\hline $\begin{array}{l}\text { Lithology } \\
\text { Pasir Tufan }\end{array}$ & $\begin{array}{c}\text { ERT/Resistivity } \\
(\text { Ohm.m })\end{array}$ & $\begin{array}{c}\text { Self Potential } \\
(\mathrm{mV})\end{array}$ \\
\hline Tuf & $1-13$ & $14-34$ \\
\hline Bahan rombakan & $31-170$ & $12-14$ \\
\hline Breksi Tufan & $72-400$ & $4-13$ \\
\hline Breksi & $>400$ & $1-3$ \\
\hline
\end{tabular}

Tabel 2. Nilai resistivitas batuan (Mohammad,dkk.,2016)

\begin{tabular}{lc}
\hline Lithology & ERT/Resistivity (Ohm.m) \\
\hline Tuf lempungan / Tuf pasiran & $1-20$ \\
\hline $\begin{array}{l}\text { perselingan tuf pasiran kasar } \\
\text { dengan breksi vulkanik }\end{array}$ & $20-160$ \\
\hline $\begin{array}{l}\text { Perpaduan breksi padu } \\
\text { dengan komponen batuan } \\
\text { beku }\end{array}$ & $>160$ \\
\hline
\end{tabular}




\section{Aliran Bahan Rombakan}

Dari data ERT, anomali ini terdapat pada lapisan dangkal dengan kedalaman 2-10 m dan memiliki nilai resistivitas $31-170 \mathrm{Ohm} . \mathrm{m}$, sedangkan dari SP nilainya adalah 5-13 mV. Apabila ditinjau dari penampang ERT dan penampang SP (Gambar 17), maka aliran bahan rombakan pada penampang ERT dan SP memiliki pola yang hampir sama yaitu melensa.

\section{Lapisan Jenuh Air/Muka Air Tanah}

Lapisan jenuh air/muka air tanah dari data ERT diindikasikan dengan nilai resistivitas 1 - 13 Ohm.m, sedangkan dari data SP diindikasikan dengan nilai 14 - 34 mV. Kedua nilai tersebut saling berkorelasi. Air memiliki konduktivitas tinggi (daya hantar listrik tinggi), oleh karena itu maka nilai resistivitas air sangat rendah yang bernilai 1 - 13 Ohm.m (konduktivitas berbanding terbalik dengan resistivitas (r)), $r=1 /$ ). Anomali SP untuk lapisan jenuh air/muka air tanah nilainya tinggi ( > $14 \mathrm{mV}$ ) karena kecepatan aliran fluida berkaitan dengan anomali potensial elektrokinetik atau SP, oleh karena itu jika kecepatan rembesan air dalam tanah semakin tinggi maka respon potensial (SP) dipermukaan akan semakin tinggi pula. Berdasarkan nilai SP dan ERT yang didapatkan, maka ke dua nilai tersebut berkorelasi dalam menentukan lapisan jenuh air.

\section{Bidang Gelincir}

Bidang gelincir dari data ERT diindikasikan dengan nilai resistivitas tinggi > $400 \mathrm{Ohm} . \mathrm{m}$, yang terdapat pada batuan breksi. Apabila diamati penampang ERT lintasan 1 sampai dengan lintasan 6, maka kedalaman dan pola bidang gelincir setiap lokasi bervariasi dengan kedalaman 2-20 m. Indikasi bidang gelincir pada data SP diperoleh secara tidak langsung, yaitu dari sebaran fluida/lapisan jenuh air yang berkaitan dengan bidang gelincir karena posisi lapisan batuan yang jenuh air berada di atas bidang gelincir.

\section{Jenis Gerakan Tanah}

Berdasarkan klasifikasi gerakan tanah Varnes (1978), maka secara umum jenis gerakan tanah yang terdapat pada penampang ERT lintasan 1 - lintasan 6 termasuk ke dalam jenis longsoran (slides) yang bergerak secara translasi. Kedalaman bidang gelincir pada jenis longsoran translasi lebih dangkal dibandingkan kedalaman bidang gelincir longsoran rotasi.

\section{KESIMPULAN}

Gerakan tanah berupa aliran bahan rombakan di Lingkung Anjung, Pasanggrahan Baru, Sumedang Selatan dapat diidentifikasi dari penampang ERT dengan pola melensa yang memiliki nilai resistivitas $31-170$ Ohm.m, sedangkan dari penampang self potential aliran bahan rombakan diindikasikan dengan pola melensa dengan nilai resistivitas: $5-13 \mathrm{mV}$.

Beberapa faktor yang menyebabkan terjadinya gerakan tanah, antara lain: adanya bidang gelincir dan peningkatan kapasitas air tanah. Bidang gelincir di daerah penelitian terdapat pada batas antara breksi (nilai resistivitas 400 - 900 Ohm.m) dengan material di atasnya. Pada bagian atas breksi terdapat lapisan jenuh air berupa muka air tanah dengan nilai resistivitas $1-15$ Ohm.m dan nilai Self Potential 14-34 mV.

Sebaran lapisan jenuh air yang telah di zonasi dari Peta Self Potential, sebagian besar terdapat di sebelah barat yang berarah utara-selatan. Sebaran lapisan jenuh air berkaitan secara tidak langsung dengan keberadaan bidang gelincir karena posisinya berada di bawah muka air tanah.

\section{UCAPAN TERIMAKASIH}

Penulis mengucapkan terima kasih kepada DRPMI Unpad yang telah mendanai penelitian ini melalui skema HIU-RFU Unpad. Ucapan terima kasih, penulis sampaikan juga kepada Lurah Pasanggrahan Baru dan masyarakat Lingkung Anjung, Pasanggrahan Baru, Sumedang Selatan yang membantu kami dalam pelaksanaan penelitian.

\section{ACUAN}

Anonim, 2008. Peta Zona Kerentanan Gerakan Tanah Kab. Sumedang, Prov. Jawa Barat. Pusat Vulkanologi Mitigasi Bencana Geologi.

Anonim, 2016 a. 4 Orang Tewas Tertimbun Longsor di Sumedang. Melalui https://regional.kompas.com/read/2016/09/21/11433411/4.orang.tewas.tertimbun.longsor.di.sumedang $[20 / 11 / 18]$ 
Anonim, 2016b. Pusat Vulkanologi Mitigasi Bencana Geologi: Laporan Singkat Pemeriksaan Gerakan Tanah Di Kecamatan Sumedang Selatan Kabupaten Sumedang Provinsi Jawa Barat. Melalui http://www.vsi.esdm.go.id/index.php/gerakan-tanah/kejadian-gerakan-tanah/1304-laporan-singkatpemeriksaan-gerakan-tanah-di-kec-sumedang-selatan-kab-sumedang-provinsi-jawa-barat [20/11/18]

Bell, R., Petschko, Röhrs, M.R., and Dix, A., 2012. Assessment of Landslide Age, Landslide Persistence and Human Impact Using Airborne 4. Laser Scanning Digital Terrain Models. Geografiska Annaler: Series A Physical Geography, 94 (1): 135-156.

Bordoni, M., Meisina, C., Valentino, R., Lu, N., Bittelli, M., and Chersich, S., 2015. Hydrological Factors Affecting Rainfall-Induced Shallow Landslides : From the Field Monitoring to a Simplified Slope Stability Analysis. Journal of Engineering Geology,193: 19-37.

Colangelo, G., Lapenna, V., Perrone, A., Piscitelli, S., and Telesca, L., 2006. 2D Self-Potential Tomographies for Studying Groundwater Flows in the Varco d; Izzo landslide (Basilicata, southern Italy). J. Engineering Geology, $88: 274-286$.

Crozier, M.J., 2010. Landslide Geomorphology: An Argument for Recognition, With Examples from New Zealand. Journal of Geomorphology, 120 (1-2): 3-15.

Chowdhury, R.N., 2010. Geotechnical Slope Analysis. CRC Press, Netherlands: 54p

Carpentier, S., Konz, M., Fischer, R., Anagnostopoulos, G., Meusburger, M., and Schoeck, K., 2012. Geophysical Imaging of Shallow Subsurface Topography and Its Implication for Shallow Landslide Susceptibility in the Urseren Valley Switzerland. Journal of Applied Geophysics, 83: 46-56

Daily, W., Ramirez, A., Binley, A. and LeBrecque, D., 2004. Electrical Resistance Tomography. Journal of The Leading Edge, 23:5

Emy, A dan Dwa, D.W, 2016. Analisa Pengaruh Kadar Air Terhadap Sifat Resistivitas dan Konduktivitas Limestone Daerah Gresik, Jawa Timur. Jurnal Fisika Batuan, 2(1): 1-5.

Gance, J., Malet, J.P., Supper, R., Sailhac, P., Ottowitz, D., and Jochum, B. 2016. Permanent Electrical Resistivity Measurements for Monitoring Water Circulation in Clayey Landslides. Journal of Applied Geophysics, 126: 98115.

Gulla, G., Aceto, L., Antronico, L., Borrelli, L., Coscarelli, R., and Perri, F., 2018. A Smart Geotechnical Model in Emergency Conditions : A Case Study of a Medium-Deep Landslide in Southern Italy. Journal of Engineering Geology, 234: 138-152.

Kodoatie, R.J., 1996. Pengantar Hidrogeologi. Andi Offset, Yogyakarta, p.82.

Korup, O., Densmore, A.L. and Schlunegger, F., 2010. The Role of Landslides in Mountain Range Evolution. Journal of Geomorphology,120 (1-2): 77-90.

Loke, M.H., 2004. Res2Dinv ver. 3.54, Rapid 2D Resistivitas and IP Inversion Using the Least-Squares Method, Geotomo Software, Malaysia: p11-36.

Malamud, B.D., Turcotte, D. L., Guzzetti, F and Reichenbach, P., 2004. Landslide Inventories and Their Statistical Properties. Journal of Earth Surface Processes and Landforms, 29 (6): 687-711.

Mohammad, F., Mardiana, U., Yuniardi, Y., Firmansyah, Y., and Alfadli, K.M., 2016. Potensi Air Tanah Berdasarkan Resistivitas Batuan di Kelurahan Cangkorah, Kecamatan Batujajar, Kabupaten Bandung-Barat. Bulletin of Scientific Contribution FTG Unpad, 14 (2):141-152.

Silitonga,P .H., 1973. Peta Geologi Lembar Bandung, Jawa, Sekala 1:100.000. Pusat Penelitian dan Pengembangan Geologi, Bandung.

Sassa, K. and Canuti, P., 2009. Landslides Disaster Risk Reduction. Springer-Verlag Berlin Heidelberg: 31p

Solberg, I.L., Long, M., Baranwal, V.C., Gylland, A.S and Ronning, J.S., 2016. Geophysical and Geotechnical Studies of Geology and Sediment Properties at a Quick-Clay Landslide Site at Esp, Trondheim, Norway. Journal of Engineering Geology, 208: 214-230.

Santoso, B., Setianto, Hasanah, M.U., Wijatmoko, B., and Mohammad, I.H., 2018. Mitigation of Land Movement Using Self Potential Method In Ling-Anjung, Sumedang Regency. Eksakta, 19 (1) :32-39 
Telford, W.M., Geldart, L.P., and Sheriff, R.E., 2004. Applied Geophysics 2 Edition. Cambridge University Press, Cambridge: 535-537.

Tsucida, T., Athapaththu, A.M.R.G., Kawabata, S., Kano, S., Hanaoka,T., and Yuri, A. 2014. Individual Landslide Hazard Assessment of Natural Valleys and Slopes Base on Geotechnical Investigation and Analysis 2014. Journal of Soil and Foundation, 54 (4): 806-819.

Uhlemann, S., Wilkinson, P.B., Chambers, J.E., Maurer, H., Merritt, A.J., Gunn, D.A., and Meldrum, P.I., 2015. Interpolation of Landslide Movements To Improve The Accuracy of 4D Geoelectrical Monitoring. Journal of Applied Geophysics, 121:93-105.

Varnes, D. J., 1978. Slope Movement Types and Processes In : Special Report 176: Landslides: Analysis and Control. Transportation and Road Research Board National Academy of Science Washington D C.

Wang, F., Okeke, A.C.U., Kogure, T., Sakai, T., Hayashi, H., 2018. Assessing the Internal Structure of Landslide Dams Subject to Possible Piping Erosion by Means of Microtremor Chain Array and Self-Potential Surveys. Journal of Engineering Geology, 234: 11-26.

Yin, Y., Li, B., Wang, W., Zhan, L., Xue, Q., Gao, Y., Zhang, N., Chen, H., Liu, T., and Li, A., 2016. Mechanism of the December 2015 Catastrophic Landslide at the Shenzhen Landfill and Controlling Geotechnical Risks of Urbanization. Journal of Engineering, 2: 230-249.

Van Bemmelen, R.W.,1949. The Geology of Indonesia Vol. 1 A. Government Printing Office, The Hauge, Amsterdam, $27 \mathrm{p}$.

Zakaria, Z., Jihadi, L.H., Sabila, Z.S., and Oscar, A.W., 2015. Simulation of Slope Stability in the Dry and Rainy Season at Jatinangor, District of Sumedang, West Java. Proceedings of The 2nd International Conference Hanoigeo "Engineering Geology in Respond to Climate Change and Sustainable Development of Infrastructure", Hanoi, Vietnam, 27-28 November 2015, pp. 365-367 